\title{
Chromosome structure and behaviour in Bursaphelenchus xylophilus (Nematoda: Parasitaphelenchidae) germ cells and early embryo
}

\author{
Koichi Hasegawa ${ }^{1,2}$, Manuel M. Mota ${ }^{3}$, Kazuyoshi Futai ${ }^{2}$ and Johji Miwa ${ }^{1,4, *}$ \\ ${ }^{1}$ Institute for Biological Function, Chubu University, 1200 Matsumoto-cho, Kasugai, 487-8501 Japan \\ ${ }^{2}$ Laboratory of Environmental Mycoscience, Graduate School of Agriculture, Kyoto University, Sakyo-ku, Kyoto, \\ 606-8502 Japan \\ ${ }^{3}$ NemaLab-ICAM, Departmento de Biologia, Universidade de Evora, 7002-554 Evora, Portugal \\ ${ }^{4}$ Laboratory of Developmental Genetics, Graduate School of Bioscience and Biotechnology, Chubu University, 1200 \\ Matsumoto-cho, Kasugai, 487-8501 Japan
}

Received: 23 January 2006; revised: 5 April 2006

Accepted for publication: 6 April 2006

\begin{abstract}
Summary - Chromosome structure and behaviour in both meiosis of the germ cells and mitosis of the embryo from fertilisation to the two-cell stage in Bursaphelenchus xylophilus were examined by DAPI staining and three-dimensional reconstruction of serial-section images from confocal laser-scanning microscopy. By this method, each chromosome's shape and behaviour were clearly visible in early embryogenesis from fertilisation through the formation and fusion of the male and female pronuclei to the first mitotic division. The male pronucleus was bigger than that of the female, although the oocyte is larger and richer in nutrients than the sperm. From the shape of the separating chromosomes at anaphase, the mitotic chromosomes appeared to be polycentric or holocentric rather than monocentric. Each chromosome was clearly distinguishable in the male and female germ cells, pronuclei of the one-cell stage embryo, and the early embryonic nuclei. The haploid number of chromosomes $(\mathrm{N})$ was six $(2 \mathrm{n}=12)$, and all chromosomes appeared similar. The chromosome pair containing the ribosomal RNA-coding site was visualised by fluorescence in situ hybridisation. Unlike the sex determination system in Caenorhabditis elegans (XX in hermaphrodite and XO in male), the system for B. xylophilus may consist of an XX female and an XY male.
\end{abstract}

Keywords - fluorescence in situ hybridisation, meiosis, mitosis, pine wood nematode, ribosomal RNA.

The pine wood nematode Bursaphelenchus xylophilus (Nematoda: Parasitaphelenchidae) is the causal agent of pine wilt disease in East Asia, destroying millions of pine trees every year in Japan. An outbreak of this disease was reported for the first time in Europe as well (Mota et al., 1999). Despite its parasitic nature, B. xylophilus can be easily maintained in the laboratory feeding on plant calli or fungi (Iwahori \& Futai, 1990). It has a large brood size with a short generation time (Mamiya, 1975) and is suitable for microscopy because of its simplicity and transparent body and embryo (Hasegawa et al., 2004). Transcriptional and functional analyses of B. xylophilus genes have been initiated by constructing ESTs (Kikuchi et al., 2004, 2005). Therefore, the establishment and improvement of basic methods for studying the molecular and cellular biology of B. xylophilus are indispensable.

The process of gametogenesis and the chromosome number of $B$. xylophilus have been previously reported (Aoyagi \& Ishibashi, 1983; Bolla \& Tamura, 1989; Bolla \& Boschert, 1993). Because of the small chromosome size and cell-destructive preparation method for staining (squashing method), it has been very difficult to observe chromosome behaviour and determine the karyotype of this nematode. Bursaphelenchus xylophilus reproduces bisexually (amphimixis), and its early embryogenesis was previously described (Hasegawa et al., 2004). In this paper, we examined the chromosome behaviour in $B$. xylophilus during gametogenesis and early embryogenesis from fertilisation to the two-cell stage embryo, without

\footnotetext{
* Corresponding author, e-mail: miwa@isc.chubu.ac.jp
} 
squashing, by DAPI staining and confocal laser-scanning microscopy. The coding regions of ribosomal RNA on the chromosomes were visualised by fluorescence in situ hybridisation (FISH), distinguishing this pair of chromosomes from the others.

\section{Materials and methods}

\section{NEMATODE}

Bursaphelenchus xylophilus isolate S-10 (originally isolated from Shimane Prefecture, Japan) was used. Methods for culturing, handling, and observing B. xylophilus were as described by Hasegawa et al. (2004), except when otherwise noted.

\section{STAINING THE GERM CELLS}

Adult male and female nematodes were transferred into a droplet of $0.1 \mathrm{M} \mathrm{NaCl}$ in the well of a slide glass (Multitest eight-well slide; ICN Biomedical Inc., Aurora, OH, USA) under a dissecting microscope and cut near the anterior region with a surgical knife to release the germ cells. The $\mathrm{NaCl}$ was completely exchanged for $-20^{\circ} \mathrm{C}$ acetone by pipetting, and the specimen was air dried and stained with $2 \mu \mathrm{g} \mathrm{ml}^{-1}$ of DAPI (4'6'-diamino2-phenylinediole dihydrochloride) in PBS (phosphatebuffered saline: $137 \mathrm{mM} \mathrm{NaCl}, 8.1 \mathrm{mM} \mathrm{Na} 2 \mathrm{HPO}_{4}$, $2.68 \mathrm{mM} \mathrm{KCl}$, and $1.47 \mathrm{mM} \mathrm{KH}{ }_{2} \mathrm{PO}_{4}$ ) for $5 \mathrm{~min}$. Stained germ cells were washed with PBS for several seconds and mounted in Vectashield (Vector Laboratories Inc., Burlingame, CA, USA) for viewing with a Zeiss Axiovert 200 microscope equipped with a confocal laser-scanning module (Zeiss LSM510).

\section{STAINING FOR EARLY EMBRYOS}

Large quantities of B. xylophilus were grown by a modified method of Evans (1970): about $5 \mathrm{mg}$ of barley and $5 \mathrm{ml}$ of distilled water were placed in $50 \mathrm{ml}$ flasks and autoclaved; after cooling to room temperature, the sterilised barley was inoculated with the nematode fungal food Botrytis cinerea and incubated at $20^{\circ} \mathrm{C}$ for about 1 week to grow a dense mat of fungal hyphae. Bursaphelenchus xylophilus was inoculated and grown at $25^{\circ} \mathrm{C}$ for 3 or 4 days. As the population of nematodes grew, the fungal hyphae gradually decreased, and, just after the hyphae had been consumed, nematodes were separated from the barley by the Baerman funnel method. Droplets of collected nematode suspension were transferred into the wells of the slide glass (Multitest eight-well slide), and the nematodes were incubated at $25^{\circ} \mathrm{C}$ for $3 \mathrm{~h}$ to lay eggs. The nematodes were washed away leaving many earlystage embryos adhering to the glass. The embryos were fixed, stained, and observed as described above for the germ cells.

Serial-section images were acquired and reconstructed into 3D images by using the LSM510 operation system and software. The series of 3D images (LSM files) were first transformed into jpeg images and then converted into AVI movie files by using AVI edit, version 01.10 (TMN Japan, http://www.tmnt.co.jp/).

\section{PROBE PREPARATION FOR FLUORESCENCE IN SITU HYBRIDISATION}

A digoxigenin-labelled 5.8S ribosomal RNA region (DIG-5.8S Rib, ca 500 bp) was synthesised from $B$. xylophilus genomic DNA by PCR with B. xylophilusspecific primers (Takeuchi et al., 2005) and PCR DIG labelling mix (Roche, Penzberg, Germany).

\section{FLUORESCENCE IN SITU HYBRIDISATION}

Early embryos were collected and fixed as described by Hasegawa et al. (2004), except that $1 \mu \mathrm{g} \mathrm{ml}^{-1}$ of colchicine was added to the water when animals were allowed to lay eggs in the slide wells, and the in situ hybridisation method described by Albertson (1984) was modified as follows. After fixation, the slides were air dried, rehydrated with $2 \times \mathrm{SSC}(0.3 \mathrm{M} \mathrm{NaCl}, 0.03 \mathrm{M}$ $\mathrm{Na}$ citrate, $\mathrm{pH} 7.0$ ), and then incubated for $1 \mathrm{~h}$ at $37^{\circ} \mathrm{C}$ with ribonuclease $\left(100 \mu \mathrm{g} \mathrm{ml}^{-1}\right.$ in $\left.2 \times \mathrm{SSC}\right)$. After ribonuclease digestion, the slides were washed twice for 5 min each with $2 \times \mathrm{SSC}$ followed by incubation for 1 to $2 \mathrm{~min}$ at room temperature with $0.7 \mathrm{M} \mathrm{NaOH}$, and then were sequentially passed through $70 \%$ and $100 \%$ ethanol and air dried. The eggs in the slide wells were covered with $\mathrm{ca} 12 \mu \mathrm{l}$ of hybridisation buffer (50\% Formamide, $10 \%$ Dextran sulphate, $2 \times$ SSC, 50 M Sodium phosphate buffer, $\mathrm{pH}$ 7.0) containing the DIG-5.8S Rib probe (10$20 \mu \mathrm{g} \mathrm{ml}^{-1}$ ), incubated for $10 \mathrm{~min}$ at $80^{\circ} \mathrm{C}$, and then incubated overnight in a moist chamber at $37^{\circ} \mathrm{C}$. The slides were washed for 5 min periods three times with wash buffer (50\% Formamide in $2 \times \mathrm{SSC})$ at $37^{\circ} \mathrm{C}$, and then three times with $2 \times \mathrm{SSC}$ at room temperature.

Washed slides were blocked with Block Ace (Dainippon Seiyaku, Osaka, Japan) for $15 \mathrm{~min}$, and incubated for $1 \mathrm{~h}$ at room temperature with mouse monoclonal antidigoxigenin antibody (Roche), which was diluted 1:500 
with antibody dilution buffer (ABDB: PBS containing 2\% BSA, $0 . \overline{1} \%$ Triton $\mathrm{X}-\overline{100}$, and $0.1 \% \mathrm{NaN}_{3}$ ). The slides were washed twice for $15 \mathrm{~min}$ each with PBST (PBS containing $0.1 \%$ Triton X-100), blocked for 15 min with Block Ace, and incubated for $1 \mathrm{~h}$ at room temperature with FITC-conjugated anti-mouse IgG (Sigma, St Louis, MO, USA) diluted 1:500 with ABDB. After the slides were washed twice for $15 \mathrm{~min}$ with PBST, they were stained with $2 \mu \mathrm{g} \mathrm{ml}^{-1}$ of DAPI for a few minutes. Slides were washed with PBST for a few seconds, and mounted in Vectashield for viewing by the Zeiss Axiovert 200 equipped with the confocal laser-scanning module (Zeiss LSM510).

\section{Results}

\section{GERM CELLS}

Both male and female $B$. xylophilus have one tubular gonad (monodelphic gonad), which extends straight forward from the cloaca (in males) or vulva (in females) (proximal region) toward the anterior (distal) region (Fig. 1A, B). The cell at the tip of the gonad is called the distal tip cell (DTC), and the distal region (DR) of the gonad forms the syncytium of mitotically dividing germline stem cells (Fig. 1C). Almost all nuclei contained condensed chromosomes visible as dots, but a few assembled together on the side of the nucleus (Fig. 1C). As the stem cells moved away from the distal region, they underwent meiosis (Fig. 1D). Different from male germ cells, which completed meiosis to become mature haploid sperm, oocytes were arrested in diakinesis until fertilisation (Fig. 1E, F). The metaphase chromosomes during spermatogenesis were highly condensed and were visible as dots (Fig. 1E). This structure had the same appearance as the oocyte polar body (Fig. 2A-C).

\section{MitOSIS FROM FERTILISATION TO TWO-CELL STAGE}

DAPI easily penetrated through the intact eggshell into the egg and intercalated into the DNA. By using this preparation method combined with confocal laserscanning microscopy, we could detect the essentially intact arrangement and behaviour of chromosomes in the cell, because the embryos had not been squashed for staining.

For viewing, stained embryos were selected that matched the developmental stages described for living embryos by Hasegawa et al. (2004). About $20 \mathrm{~min}$ af- ter its passage through the oviduct-quadricolumella connecting passage (OQP), the matured oocyte is fertilised, the eggshell is formed, and the oocyte resumes meiosis (Fig. 2A-C). The sperm was seen as a dot positioned at the future anterior side of the embryo at that time, and six chromosomes located at the lateral mid-point position were clearly visible inside the first polar body (Fig. 2B, C). After the completion of oocyte meiosis, male and female pronuclei were reconstructed with vesicles (Fig. 2DF). The male pronucleus was slightly bigger than the female one, and the chromosomes were dispersed throughout the periphery of the pronucleus (Fig. 2E, F). During the migration of the two pronuclei, chromosomes became condensed in the prophase stage (Fig. 2G, H), and six chromosomes were visible in each pronucleus (Fig. 2H). After meeting, the two juxtaposed pronuclei moved to the centre of the zygote, rotated 90 degrees (Fig. 2I, J) whereupon their membranes broke down, and fused. The pairs of chromatids were fused and aligned along the metaphase plate (Fig. 2K-M). The arrangement of the chromatid pairs was characteristic; chromatids were arranged horizontally to each other, and the longitudinal axes of the chromatids were perpendicular to that of the embryo (Fig. 2L, M). The posterior MTOC (microtubule organising centre) moved posteriorly at anaphase, the chromatids were divided anterior-posteriorly (Fig. 2NP), followed by unequal cytoplasmic division (Fig. 2Q, $\mathrm{R}$ ), and the two-cell stage embryo was formed (Fig. 2S). Nuclear membranes were reconstructed (Fig. 2R), and the chromosomes dispersed again to the periphery of the nuclei (Fig. 2T). It took $52.6 \pm 7.7 \mathrm{~min}\left(\mathrm{n}=7\right.$, at $\left.25^{\circ} \mathrm{C}\right)$ from oviposition to the two-cell stage when embryogenesis was observed microscopically on an agar pad (Hasegawa, unpubl.).

FISH FOR VISUALISING THE CHROMOSOMAL REGION CODING RIBOSOMAL RNA

We prepared the metaphase chromosomes of the blastomere in early embryos for karyotyping, because chromosome behaviour in gametogenesis was not suitable for karyotyping. The metaphase karyotype of B. xylophilus $\mathrm{S}-10$ consisted of 12 chromosomes in all embryos examined ( $\mathrm{n}=10+$, Fig. 3A). Similar to that previously described, all six pairs of haploid chromosomes were present in both the male and female pronuclei, and thus no obviously defined sex chromosomes were observed (Aoyagi \& Ishibashi, 1983; Bolla \& Tamura, 1989; Bolla \& Boschert, 1993). 

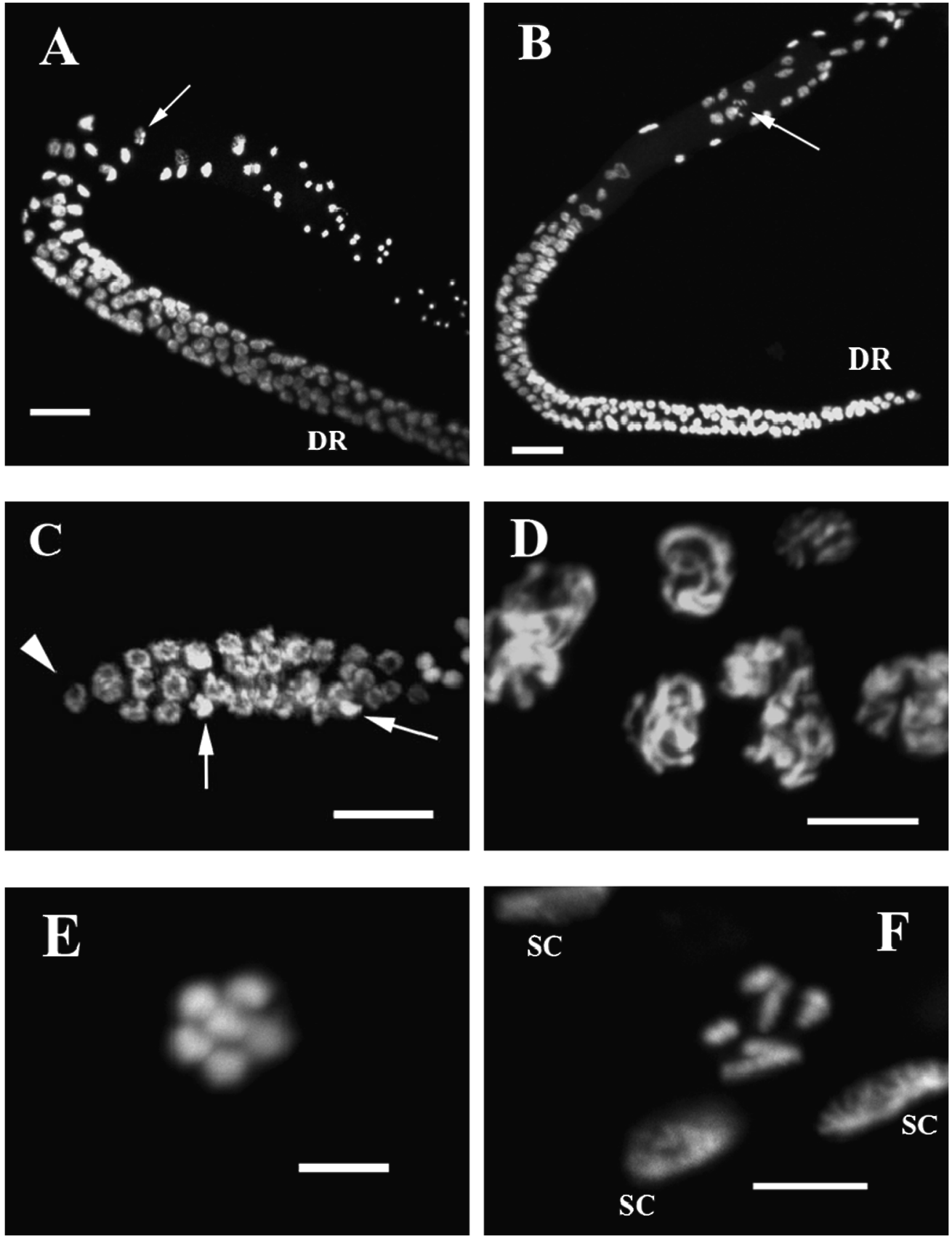

Fig. 1. Confocal laser-scanning microscope images (LSM) of adult Bursaphelenchus xylophilus male and female germ cells. A: Male germ cell, arrow indicates condensed chromosomes during meiosis; B: Female germ cell, arrow indicates chromosomes arrested at diakinesis; $C$ : Male germ nuclei at the distal region of gonad arm, proliferating mitotically. Arrowhead indicates the somatic distal tip cell (DTC), and arrows indicate dividing nuclei; D: Male germ cells in meiotic zone possess pachytene nuclei; E: High magnification of the male germ cell shown in A; F: High magnification of the female germ cell shown in B. DR, distal region; SC, somatic seam cell. (Scale bars: $A, B=20 \mu \mathrm{m} ; C=10 \mu \mathrm{m} ; D, F=5 \mu \mathrm{m} ; E=2 \mu \mathrm{m}$.) 

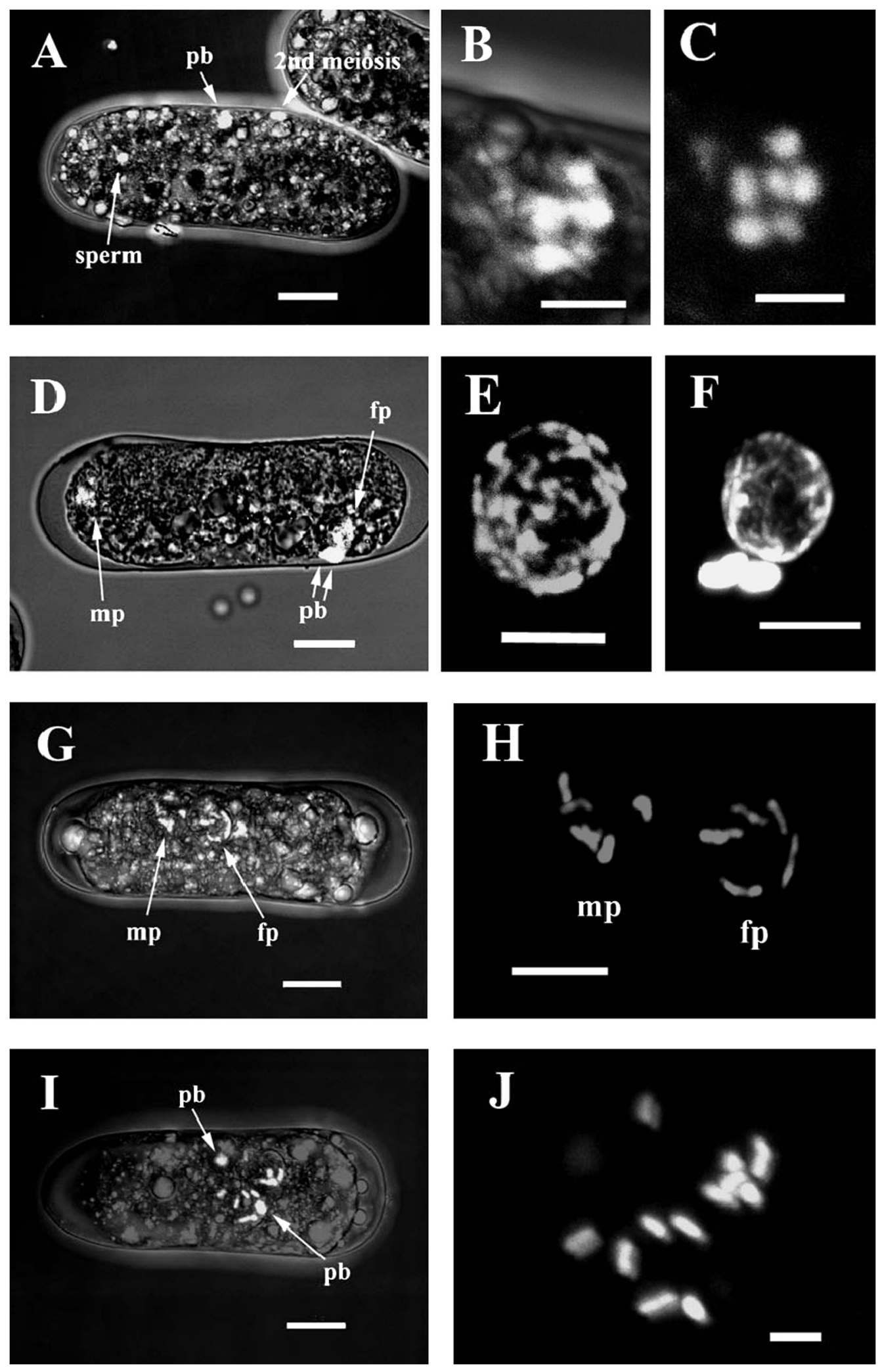

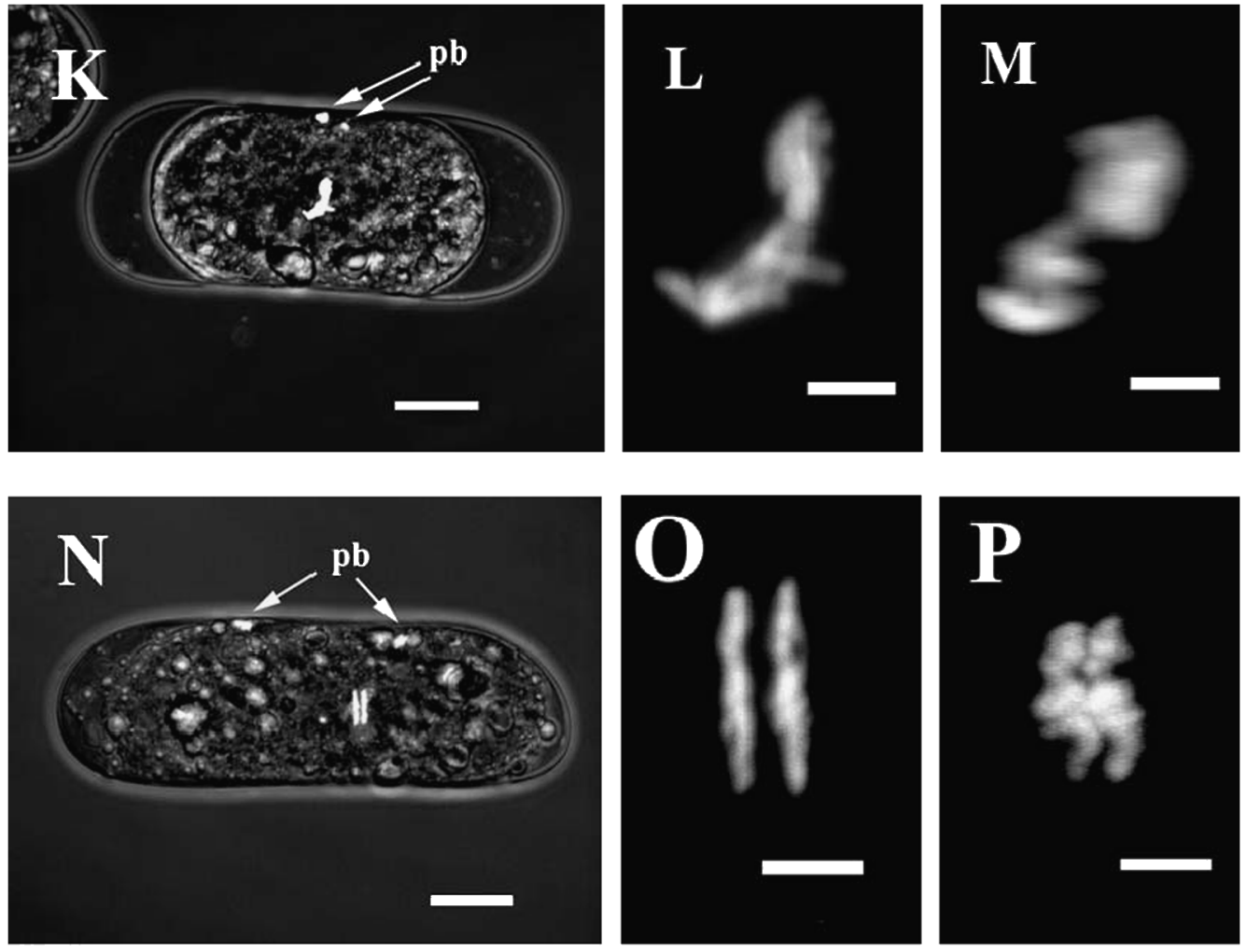

\section{D}
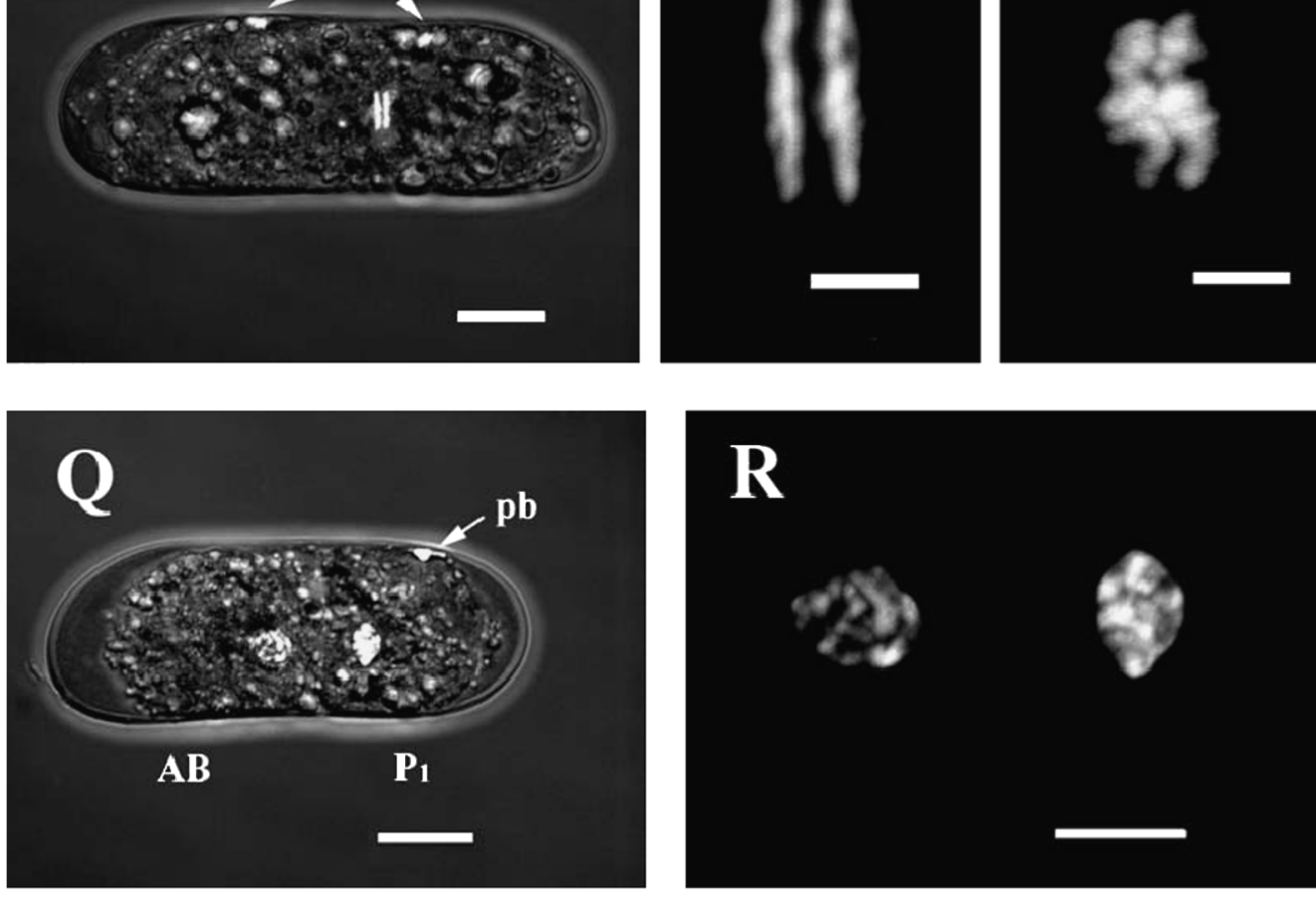

$\mathbf{R}$

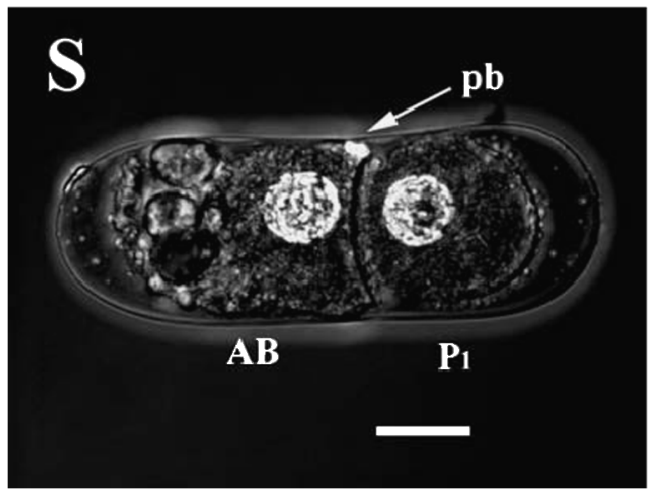

$\mathbf{T}$
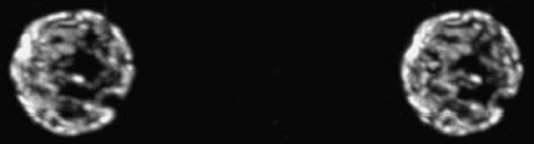
A digoxigenin-labelled 5.8 $\mathrm{S}$ ribosomal RNA probe was synthesised from the B. xylophilus genome, hybridised with interphase nuclei or metaphase chromosomes in early embryos, and visualised with FITCconjugated antibody. One pair of the fluorescence signals was visible in all observed interphase nuclei or metaphase chromosomes (Fig. 3B, C). The regions coding for ribosomal RNA were mapped at the end of the chromosomes (Fig. 3C).

\section{Discussion}

The reproductive system of nematodes comprises a somatic gonad and germ cells, and the somatic gonad consists of the distal tip cell (DTC), gonadal sheath cells (SC), spermatheca, uterus, seminal vesicle, and vas deferens (atlas of C. elegans anatomy, http://www.wormatlas.org/ handbook/contents.htm). In C. elegans, the reproductive system develops from two somatic gonad precursor cells (Z1 and Z4 cells) and two germline precursor cells (Z2 and $\mathrm{Z} 3$ cells). The $\mathrm{Z} 1$ and $\mathrm{Z} 4$ cells (DTCs) lead the elongation of the two gonadal arms anteriorly or posteriorly, and promote mitosis and/or inhibit meiosis of the germ cells during development (Hansen et al., 2004). Other species belonging to the order Rhabditida also have two somatic gonad precursor cells and two germ cell precursors. Two DTCs in these species migrate anteriorly or posteriorly but the posterior DTC is eliminated by programmed cell death to leave a monodelphic gonad (Felix \& Sternberg, 1996). In the B. xylophilus second-stage juvenile, the gonadal primordial cells comprise two small cells and two larger cells (Ishibashi et al., 1978). The posterior part of the gonad in the adult female, called the post-vulval uterine branch (Ishibashi et al., 1978) or post- vulval sac, extends from the vulva to the tail and has lost the ability to produce germ cells. It is interesting and important for studying such biological insignia as chromosomal evolution and sex determination to examine the gonadal development in B. xylophilus and compare it with those for other Bursaphelenchus species.

The mitotic cell division of B. xylophilus was observed, and stages were determined by chromosome shape and behaviour from fertilisation to the two-cell stage (Fig. 2). As blastomeres become smaller as embryogenesis proceeds, the chromosome behaviour and arrangement could not be clearly observed in the late-stage embryo.

After fertilisation and the completion of meiosis, male and female pronuclei were formed. The positions of male pronucleus, female pronucleus, and polar bodies observed in the present study matched exactly with those reported previously (Hasegawa et al., 2004); that is, the pronucleus associated with two polar bodies located at the lateral midpoint position of the embryo was considered as a female pronucleus, and the other located at the anterior pole of the longitudinal axis was considered as a male pronucleus. In B. xylophilus, the male pronucleus was bigger than that for the female, although the oocyte was larger and richer in nutrients than the sperm (Fig. 2D-F). This might reflect the existence of differences between male and female gametes at the genomic level. Although only a few paternally expressed genes are known in C. elegans (Browning \& Strome, 1996), the sperm has an essential role in embryogenesis since it brings not only a haploid genome into the oocyte, but also the two centrosomes, and stimulates the completion of oocyte meiosis and eggshell formation (Goldstein \& Hird, 1996). In B. xylophilus, sperm might also bring centrosomes into the oocyte, and it

Fig. 2. Chromosome behaviour in Bursaphelenchus xylophilus from fertilisation to the two-cell stage. A: Fertilised egg, just after extrusion from the vulva (oviposition). The sperm is seen as a dot at the future anterior end of the embryo (left side of the plate); $B:$ High magnification of the first polar body shown in A. Merged view of the bright field and fluorescence images; $C$ : Fluorescence-only image of the 1st polar body, six chromosomes are seen; D: Rearrangement of male ( $\mathrm{mp}$ ) and female ( $\mathrm{fp}$ ) pronuclei; E: High magnification of male pronucleus; F: High magnification of female pronucleus. 1st and 2nd polar bodies are seen next to the female pronucleus. G: Pronuclear meeting; H: High magnification of two pronuclei; I: Rotation of the two juxtaposed nuclei; J: High magnification of the juxtaposed nuclei shown in I. Each pronucleus consists of six haploid chromosomes. The two polar bodies seen in I are out of focal plane in this magnification; K: Mitotic metaphase after fusion of the two pronuclei; L: High magnification of chromosomes arranged along the metaphase plate; M: Same image as in L seen from 30 degrees-forward diagonal; N: Mitotic anaphase, segregating chromosomes; $O$ : High magnification of the segregating chromosomes in N; P: Same image as in O from 30 degrees-forward diagonal; $Q$ : End of mitotic telophase, with cytokinesis completed; $R$ : High magnification of $Q$. The AB cell nucleus is on the left and that for the $P_{1}$ cell is on the right. Nuclear membranes are reconstructed in the sister blastomeres; $S$ : two-cell stage embryo; T: Stereo image of $P_{1}$ nucleus ( $p b$, polar body; mp, male pronucleus; fp, female pronucleus. Anterior is left.) (Scale bars: A, D, G, I, K, N, Q, S=10 $\mu m ; E, F, H, R$ $=5 \mu \mathrm{m} ; B, C, J, L, M, O, P=2 \mu \mathrm{m}$.) 

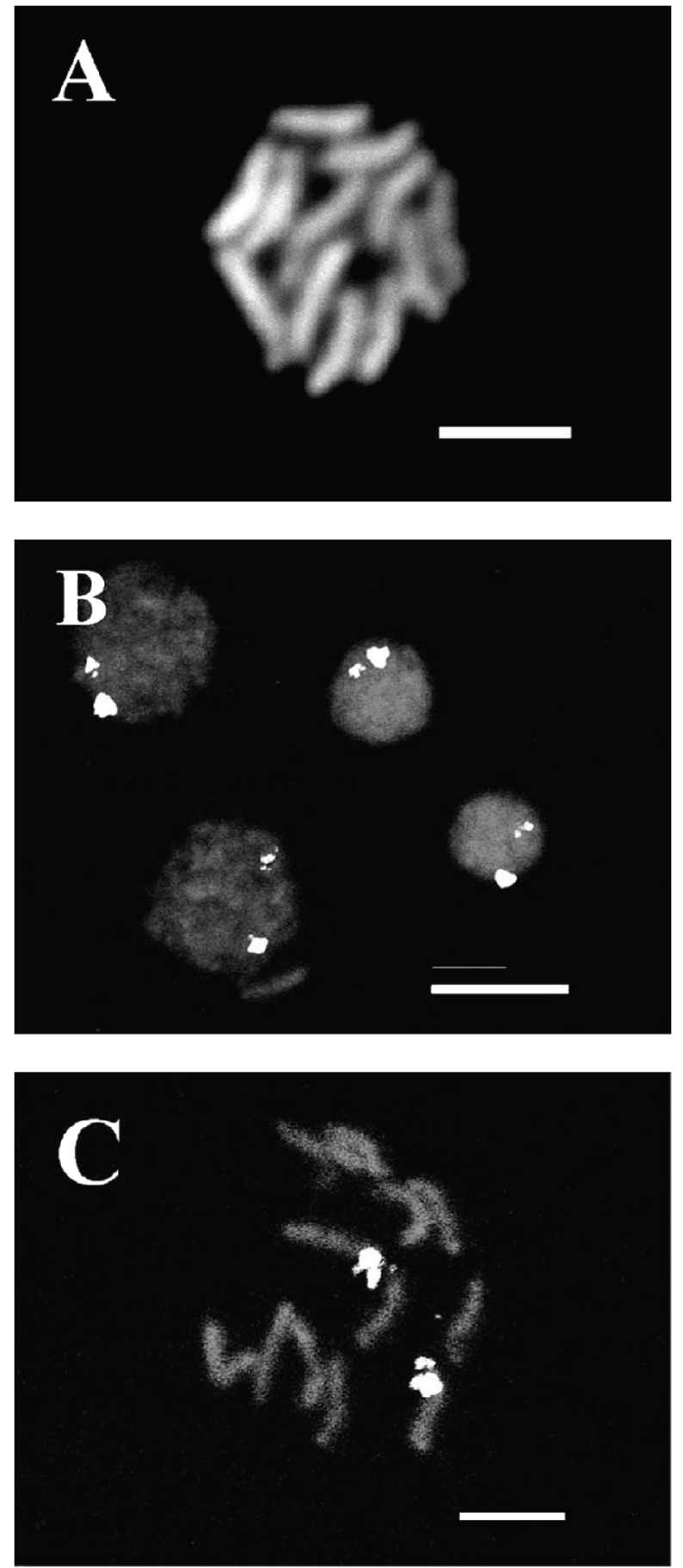

Fig. 3. Chromosomes of Bursaphelenchus xylophilus hybridised in situ with the DIG-5.8S Rib probe and visualised with FITC. A: Metaphase chromosomes in two-cell stage embryo, $2 n=12$. Stained only with DAPI; B: Interphase nuclei in early embryo; $C$ : Metaphase chromosomes in early embryo. (Scale bars: $A=$ $2 \mu \mathrm{m} ; B=10 \mu \mathrm{m} ; C=5 \mu \mathrm{m}$.) generates the anterior-posterior axis formation (Hasegawa et al., 2004).

Mitotic chromosomes of almost all nematodes have diffuse kinetochores, which form along the entire length of their chromosomes (Albertson et al., 1997). These chromosomes are sometimes referred to as holocentric. From the shape of the segregating chromosomes at anaphase (Fig. 2N-P), the mitotic chromosomes of B. xylophilus were observed to be holocentric or at least polycentric. No special sequences are thought to be required for the segregation of holocentric chromosomes in C. elegans (Albertson et al., 1997), and assembled transformed DNA can be replicated as an extrachromosomal array and distributed into daughter cells without its insertion into the host genome (Mello et al., 1991). Although the B. xylophilus germ cells in the distal region of the gonad constituted the syncytium (Fig. 1), the tube-shaped gonadal system was too small (about $20 \mu \mathrm{m}$ in width, Fig. $2 \mathrm{~N}$, O) to introduce DNA or RNA by microinjection, and no construction of transgenic B. xylophilus was reported so far. However, we believe that it should be possible to establish a transformation technique, such as by particle bombardment or electroporation, which should open the way to functional studies of genes in B. xylophilus.

Chromatin diminution, such as caused by chromosomal rearrangement exhibited in the early embryogenesis of some Ascarididae nematodes or Panagrellus redivivus, which results in differentiation of the soma-germ cell or determination of male-female sex (Muller \& Tobler, 2000), was not observed in B. xylophilus embryogenesis from fertilisation through the two-cell stage.

The determination of male or female sex relies on a chromosome-based mechanism in almost all animal species. In this study, the haploid chromosome number detected in all B. xylophilus male and female germ cells examined was six, and the morphology of all six chromosomes was apparently identical with one another in the male and female germ cells (Fig. 1), pronuclei of the one-cell stage embryo (Fig. 2), and nucleus of the early embryo (Fig. 3A). As in all the plant-parasitic nematodes reported so far (Goldstein, 1981), the sex determination system in B. xylophilus does not appear to be of the XO type. The sex of B. xylophilus might be determined by an XX/XY system, or other multiple sex chromosome systems, such as that for Ascaris suum (Goldstein, 1981). In C. elegans, sex regulation genes are scattered among various chromosomes; any one of the autosomes except for chromosome (LG) has the potential to become a sex chromosome by mutation 
(Hodgkin, 2002). Some other sex determination systems and reproductive systems are known in nematodes, such as environmental control (Triantaphyllou, 1971; Harvey \& Viney, 2001). Essentially a 1:1 ratio of males to females was observed in B. xylophilus extracted from either pine trees or the vector beetle Monochamus alternatus and also treated with high-temperature (Takemoto, Kyoto University, Japan, pers. comm.). Thus, we suppose that they should reproduce bisexually in the parasitic stage, as well as in the free-living mycetophagous stage observed here. There might be some variations in other isolates of this species.

Although the DIG-5.8S Rib probe consisted of only about $500 \mathrm{bp}$, we could clearly detect one pair of fluorescence signals from the interphase nuclei or metaphase chromosomes in early embryos (Fig. 3B, C). In the cases of other B. xylophilus genes (Bx-unc-22, Bx-tbb-1,Bx$d a f-21)$ that exist as only one copy in the genome, we could not detect FISH signals by using the 1 to $2 \mathrm{~kb}$ DIG probe and following the same protocol as in this experiment (Hasegawa, unpubl.). Several copies of ribosomal RNA genes (from one to several thousands) exist in the eukaryote haploid genome and are dispersed among several chromosomes, comprising a distinct nucleolar organiser (Moss \& Stefanovsky, 1995). Ribosomal genes may exist as several copies assembled in one position of the $B$. xylophilus genome such as those of $C$. elegans, which are assembled at the right end of the LG and repeated 55 times as a tandem array (Files \& Hirsh, 1981; Albertson, 1984; Albertson et al., 1997), although it should be pointed out that still other ribosomal genes, which are most likely not densely clustered, might be dispersed on other parts of the same or other chromosomes.

Although the morphology of all the B. xylophilus chromosomes was apparently identical, we could distinguish one pair of chromosomes from the others by using a ribosomal RNA probe. Similarly, we should be able to analyse the linkage groups of genes that have already been cloned and distinguish individual chromosomes by amplifying resolution. Cloning of the male-specific chromosome (Y chromosome) sequence by using RAPD-PCR (Random amplified polymorphic DNA) and FISH methods should prove to be a useful tool for revealing the sex determination system in $B$. xylophilus.

\section{Acknowledgements}

We thank Mr Shuhei Takemoto, Kyoto University, and Ms Satsuki Miwa, Viva Informatica, for useful comments and careful reading of this manuscript. We also thank Ms Yuko Takeuchi, Kyoto University, for generous gift of B. xylophilus ribosomal RNA primers. This work was supported by a JSPS research fellowship to $\mathrm{KH}$ and a Special Research Fund of Chubu University and a research grant from the Chubu University Institute for Biological Function to Johji Miwa.

\section{References}

Albertson, D.G. (1984). Localization of the ribosomal genes in Caenorhabditis elegans chromosomes by in situ hybridization using biotin-labeled probes. EMBO Journal 3, 12271234.

Albertson, D.G., Ross, A.M. \& Villeneuve, A.M. (1997). Chromosome organization, mitosis, and meiosis. In: Riddle, D.L., Blumenthal, T., Meyer, B.J. \& Priess, J.R. (Eds). C. elegans. Cold Spring Harbor, NY, USA, Cold Spring Harbor Laboratory Press, pp. 47-78.

AoyAgi, M. \& IshiBAshi, N. (1983). Gametogenesis of the pine wood nematode, Bursaphelenchus xylophilus. Japanese Journal of Nematology 13, 20-25.

Bolla, R.I. \& Boschert, M. (1993). Pinewood nematode species complex: interbreeding potential and chromosome number. Journal of Nematology 25, 227-238.

Bolla, R.I. \& TAMURA, H. (1989). Mating potential and chromosome number of some Japanese and U.S. populations of the pine wood nematode, Bursaphelenchus xylophilus. Japanese Journal of Nematology 19, 7-12.

Browning, H. \& Strome, S. (1996). A sperm-supplied factor required for embryogenesis in C. elegans. Development 122 , 391-404.

Evans, A.A.F. (1970). Mass culture of mycophagous nematodes. Journal of Nematology 2, 99-100.

Felix, M. \& SternberG, P.W. (1996). Symmetry breakage in the development of one-armed gonads in nematodes. Development 122, 2129-2142.

Files, J.G. \& Hirsh, D. (1981). Ribosomal DNA of Caenorhabditis elegans. Journal of Molecular Biology 149, 223240.

Goldstein, P. (1981). Sex determination in nematodes. In: Zuckerman, B.M. \& Rohde, R.A. (Eds). Plant parasitic nematodes, Vol. 3. New York, USA, Academic Press, pp. 3760.

Goldstein, B. \& Hird, S.N. (1996). Specification of the anteroposterior axis in Caenorhabditis elegans. Development $122,1467-1474$.

Hansen, D., Wilson-Berry, L., Dang, T. \& Schedl, T. (2004). Control of the proliferation versus meiotic development decision in the $C$. elegans germline through regulation of GLD-1 protein accumulation. Development 131, 93-104. 
Harvey, S.C. \& Viney, M.E. (2001). Sex determination in the parasitic nematode Strongyloides ratti. Genetics 158, 1527-1533.

Hasegawa, K., Miwa, S., Futai, K. \& Miwa, J. (2004). Early embryogenesis of the pinewood nematode Bursaphelenchus xylophilus. Development, Growth and Differentiation 46, 153-161.

HodGKIN, J. (2002). Exploring the envelope: systematic alteration in the sex-determination system of the nematode Caenorhabditis elegans. Genetics 162, 767-780.

Ishibashi, N., AOYAGI, M. \& Kondo, E. (1978). Comparison of the gonad development between the propagative and dispersal forms of pine wood nematode, Bursaphelenchus xylophilus. Japanese Journal of Nematology 8, 28-31.

IWAHORI, H. \& FUTAI, K. (1990). Propagation and effects of the pine wood nematode on calli of various plants. Japanese Journal of Nematology 20, 25-36.

Kikuchi, T., Jones, J.T., Aikwawa, T., Kosaka, H. \& OgurA, N. (2004). A family of glycosyl hydrolase family 45 cellulases from the pine wood nematode Bursaphelenchus xylophilus. FEBS Letters 572, 201-205.

Kikuchi, T., Shibuya, H. \& Jones, J.T. (2005). Molecular and biochemical characterization of an endo-beta-1,3glucanase from the pinewood nematode Bursaphelenchus xylophilus acquired by horizontal gene transfer from bacteria. Biochemical Journal 389, 117-125.
MAMIYA, Y. (1975). [The life history of the pine wood nematode, Bursaphelenchus lignicolus.] Japanese Journal of Nematology 5, 16-25.

Mello, C.C., Kramer, J.M., Stinchcomb, D. \& AmBROS, V. (1991). Efficient gene transfer in C. elegans: extrachromosomal maintenance and integration of transforming sequences. EMBO Journal 10, 3959-3970.

Moss, T. \& STEFANOVSKY, V.Y. (1995). Promotion and regulation of ribosomal transcription in eukaryotes by RNA polymerase. Progress in Nucleic Acid Research and Molecular Biology 50, 25-66.

Mota, M.M., Braasch, H., Bravo, M.A., Penas, A.C., Burgermeister, W., Metge, K. \& Sousa, E. (1999). First report of Bursaphelenchus xylophilus in Portugal and in Europe. Nematology 1, 727-734.

Muller, F. \& TOBleR, H. (2000). Chromatin diminution in the parasitic nematodes Ascaris suum and Parascaris univalens. International Journal for Parasitology 30, 391399.

TAKeUchi, Y., KanZaKi, N. \& Futai, K. (2005). A nested PCR-based method for detecting the pine wood nematode, Bursaphelenchus xylophilus, from pine wood. Nematology 7 , 775-782.

TRIANTAPHYLlOU, A.C. (1971). Genetics and cytology. In: Zuckermann, B.M., Mai, W.F. \& Rohde, R.A. (Eds). Plant parasitic nematodes, Vol. 2. New York, USA, Academic Press, pp. 1-34. 